\title{
FLUCTUATION TECHNIQUE FOR INVESTIGATION OF ULTRAFAST PROCESSES *
}

\author{
A. Matulionis \\ Fluctuation Research Laboratory, Semiconductor Physics Institute, A. Goštauto 11, LT-01108 Vilnius, Lithuania
}

Received 11 June 2007

\begin{abstract}
Microwave fluctuations contain information on hot-electron energy relaxation, intervalley transfer, real-space transfer, and other ultrafast electronic processes in semiconductors and semiconductor structures. Based on this, the novel fluctuation technique was developed for investigation of ultrafast hot-phonon effects in two-dimensional (2D) and three-dimensional (3D) channels of importance for high-speed electronics. The hot-phonon lifetime (deduced from the hot-electron fluctuations) is in good agreement with the a posteriori reported data obtained through femtosecond-laser pump-probe experiments. Moreover, the fluctuation technique demonstrates the unique experimental possibility to study the lifetime as a function of the electron temperature in a voltage-biased 2D channel, while neither Raman photon scattering nor phonon-assisted inter-sub-band absorption has provided data of this sort as yet.
\end{abstract}

Keywords: microwave noise, two-dimensional channels, GaN, high electric fields, hot phonons

PACS: 73.50.Fq, 73.50.Td, 73.61.Ey, 73.63.Hs

\section{Introduction}

Fluctuations in electric circuits are temporary deviations of variables (current, voltage, resistance, frequency, etc.) either from their long-term averages or from some regular time-dependent signals. The ultimate accuracy for electrical measurements and signal processing depends on the fluctuations. The fluctuations appear inevitably, they originate from microscopic electronic processes, and, consequently, contain information on the latter. This diagnostic aspect is discussed in the paper.

According to the universal fluctuation-dissipation theorem, the thermal-equilibrium spectra of fluctuations and response (to a weak external force) are identical. Consequently, measuring fluctuations at equilibrium provides no additional information which is not available from the response measurements. However, advances in instrumentation and communication increasingly depend on semiconductor electronics, where deviations from equilibrium play a major role. In particular, when an applied high electric field heats electrons, their chaotic motion is enhanced, and hotelectron fluctuations acquire features absent at equilibrium [1]. The experimental techniques, based on hot-

\footnotetext{
* The report presented at the 37th Lithuanian National Physics Conference, 11-13 June 2007, Vilnius, Lithuania.
}

electron fluctuations, are powerful tools for diagnosing non-equilibrium states in semiconductors subjected to high electric fields [2]. The fluctuation techniques have been successfully exploited for experimental investigation of hot-electron energy relaxation, intervalley transfer, real-space transfer, hot-phonon effects, and other ultrafast processes in semiconductors and semiconductor structures of interest for high-speed electronics $[1-4,6,7]$.

Let us illustrate the above statements on an example of hot-phonon-controlled electronic processes. The term "hot phonons" stands for the non-equilibrium longitudinal optical (LO) phonons emitted by hot electrons [5]. Accumulation of hot phonons introduces additional friction for the drifting electrons, modifies electron energy dissipation, enhances hot-electron temperature, and thus has an effect on performance of highspeed transistors $[6,7]$.

High electron mobility transistors (HEMTs) are among the most important devices of high-speed electronics. A HEMT contains a two-dimensional (2D) channel confined in a quantum-well in an undoped semiconductor embedded between two barrier layers. InGaAs-channel HEMTs are the fastest transistors; their cut-off frequency exceeds $600 \mathrm{GHz}$ [8]. GaNchannel HEMTs are the most promising for power application; their cut-off frequency approaches $200 \mathrm{GHz}$ 
$[9,10]$. The frequency of operation of a GaN channel is essentially lower than that of an InGaAs channel. This difference is caused, in part, by hot phonons: the hot-phonon effects are stronger in nitrides, as compared with arsenides [6].

The hot-phonon effects are often treated in terms of hot-phonon lifetime $[5,11,12]$. The most direct technique for measuring the lifetime is pump-probe Raman scattering [13]. A pump pulse of a femtosecond laser generates photoelectrons in a crystal of a semiconductor. The high-energy electrons emit hot phonons, and the latter scatter the probe photons. The hot-phonon lifetime is determined from the decay, after the pump pulse, of the anti-Stokes line intensity. The lifetime has been measured for most III-V compound semiconductors. At a low density of electrons, the lifetime of hot phonons exceeds several picoseconds. For example, $\tau_{\mathrm{ph}} \sim 3 \mathrm{ps}$ in GaN at room temperature [14]. The lifetime decreases as the pump intensity increases $[13,15]$. For $\mathrm{GaN}$, the lifetime changes from $2.5 \mathrm{ps}$ at electron density of $\sim 10^{16} \mathrm{~cm}^{-3}$ down to $350 \mathrm{fs}$ at $2 \cdot 10^{19} \mathrm{~cm}^{-3}$ [15]. The model of coupled plasmon-phonon modes explains the dependence of the lifetime on the electron density [16].

The femtosecond time-resolved Raman experiments were carried out on multi-quantum-well structures as well $[17,18]$. The structures contained 30-60 empty quantum wells, the experiment was successful at a low electron density at low temperature. The obtained lifetime values were close to those reported for uniform bulk semiconductors of similar composition. The Raman technique for the lifetime measurement has never been applied to a 2D channel with a degenerate electron gas used in high-speed transistors.

The alternative techniques for hot-phonon lifetime measurement are based on hot-electron fluctuations [19] and time-resolved hot-phonon-assisted inter-subband absorption [20]. The fluctuation technique has yielded the first experimental result, 350 fs [19], on the hot-phonon lifetime measured in a 2D channel with a degenerate electron gas of interest for high-power microwave HEMTs. Two years later, the value of $380 \mathrm{fs}$ is obtained for a similar 2D channel from the absorption experiment [20]. These lifetime values, $350 \mathrm{fs}$ and 380 fs, measured for AlGaN / GaN structures with 2D channels located in $\mathrm{GaN}$, are close to the Raman lifetime value of 350 fs obtained for bulk GaN under extremely high pump intensity [15].

The diagnostic possibilities of the technique based on hot-electron fluctuations are reconsidered in this paper. The results for different $2 \mathrm{D}$ and $3 \mathrm{D}$ channels are compared with those obtained by alternative techniques.

\section{Fluctuation technique}

Ultrafast hot-electron fluctuations dominate in the range of microwave frequencies where slow fluctuations (generation-recombination, $1 / f$ fluctuations) are of negligible intensity. The measurements are carried out on gateless channels supplied with two ohmic electrodes and subjected to a high electric field applied along the channel. The hot-electron fluctuations cause current fluctuations, the latter generate electromagnetic radiation (noise power) emitted into the load (the input of the sensitive radiometer of microwave power). It is a convention to consider the noise power for matched impedances of the sample and the load, unless stated otherwise. Under this condition, the noise power is called the available noise power.

The available noise power $P_{\mathrm{n}}(f)$ emitted into a fixed frequency band $\Delta f$ around a frequency $f$ can be estimated by comparing it with the power radiated into the same frequency band by an absolutely black body kept at a known temperature. In case of equal powers, the equivalent noise temperature $T_{\mathrm{n}}(f)$ equals the absolute temperature of the reference black body $T_{\mathrm{bb}}$. The equivalent noise temperature, or noise temperature, is defined as follows [2]:

$$
T_{\mathrm{n}}(f)=\frac{P_{\mathrm{n}}(f)}{k_{\mathrm{B}} \Delta f} .
$$

The equilibrium noise is white in the classical range of frequencies $h f \ll k_{\mathrm{B}} T_{0}$, the noise temperature equals the ambient temperature, $T_{\mathrm{n}}=T_{0}$. Unlike this, the hot-electron noise temperature $T_{\mathrm{n}}(f)$ depends on frequency and electric field. Even in an isotropic medium, the hot-electron noise differs in the directions parallel and transverse to the current.

Frequent electron-electron collisions support the electron temperature approximation. For quasi-elastic scattering, the noise temperature is expressible as follows [21]:

$$
\begin{aligned}
& \left(T_{\mathrm{n}}\right)_{\perp}=T_{\mathrm{e}}, \\
& \left(T_{\mathrm{n}}\right)_{\|}=T_{\mathrm{e}}\left[1+\frac{T_{\mathrm{e}}}{4\left(T_{\mathrm{e}}-T_{0}\right)}\left(\frac{\mu_{\|}}{\mu_{\perp}}+\frac{\mu_{\perp}}{\mu_{\|}}-2\right)\right],
\end{aligned}
$$

where $T_{\mathrm{e}}$ is the electron temperature, $\left(T_{\mathrm{n}}\right)_{\|}$and $\left(T_{\mathrm{n}}\right)_{\perp}$ are the longitudinal and transverse noise temperatures, $\mu_{\|}$and $\mu_{\perp}$ are the ac mobilities. One can see that $T_{\mathrm{n}} \approx$ $T_{\mathrm{e}}$ if $\mu_{\perp} \approx \mu_{\|}$. 


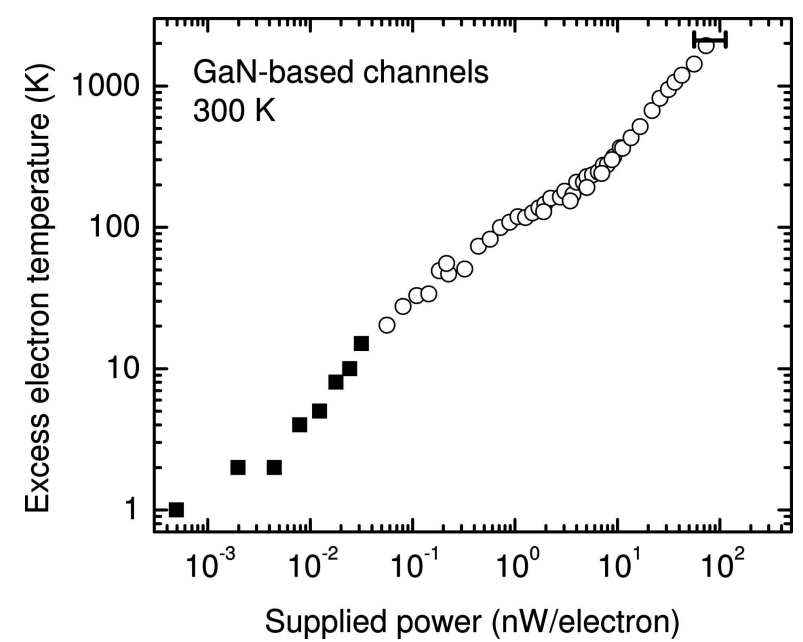

Fig. 1. Dependence of excess electron temperature $T_{\mathrm{e}}-T_{0}$ on supplied electric power (per electron) for GaN-based channels estimated from noise (circles [6]) and optical spectra (horizontal bar [26], squares [27]).

Expression (3) does not hold for a degenerate hot electron gas [22]: the Pauli constraint causes an additional correlation of the final single-electron states generated during each electron-electron collision. Hot phonons complicate the problem further on: the LOphonon distribution differs from the equilibrium one. Fortunately, at a high density of electron gas present in a $2 \mathrm{D}$ channel, the hot-electron temperature approximation holds [23, 24]. Moreover, a quasi-equilibrium hot subsystem forms because of intense electron-LOphonon scattering [19]. The quasi-equilibrium means that the equivalent hot-phonon temperature is close to the hot-electron temperature: experiments show that the difference makes only several percent in nitride 2D channels $[6,7]$. According to Monte Carlo simulation, the mentioned quasi-equilibrium supports a useful approximate equality, $T_{\mathrm{n}} \approx T_{\mathrm{e}}$, valid for a $2 \mathrm{D}$ channel located in $\mathrm{GaN}$ within several percent [25]. Figure 1 illustrates that the electron temperature estimated from the noise experiment [6] is in a satisfactory agreement with the available independent optical data [26, 27].

The experimental fluctuation technique for estimation of the hot-phonon lifetime [19] is developed after a careful analysis of different sources of hot-electron fluctuations in 2D channels with degenerate electron gas $[4,28-30]$. The technique works best at electric fields and ambient temperatures where the electronLO-phonon scattering is the dominant power dissipation mechanism. A useful check is obtained when the dissipated power $P_{\mathrm{d}}$ is plotted against the inverse noise

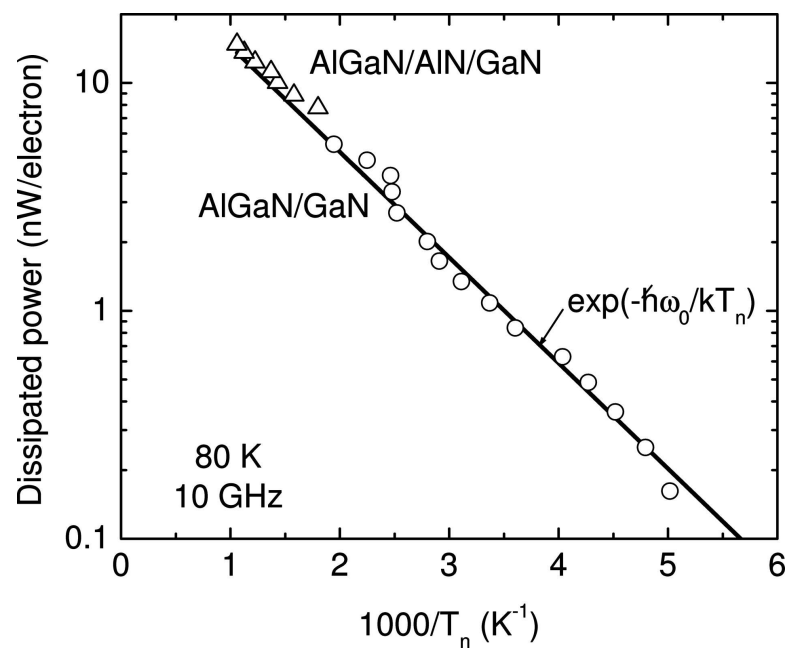

Fig. 2. Arrhenius plot of dissipated power (per electron) against inverse noise temperature at $T_{0}=80 \mathrm{~K}$ for $2 \mathrm{D}$ channels: AlGaN/ $\mathrm{AlN} / \mathrm{GaN}$ (triangles) and AlGaN/GaN (circles [19]). Solid line is Eq. (4).

temperature (Fig. 2). Solid line stands for the exponential dependence:

$$
P_{\mathrm{d}}=A \exp \left[-\frac{\hbar \omega_{0}}{k_{\mathrm{B}} T_{\mathrm{n}}}\right]
$$

where $A=F \hbar \omega_{0} / \tau_{\text {ph }}$ contains the lifetime and the form factor $F$.

The experimental data (Fig. 2, symbols) can be fitted with Eq. (4) where the activation energy equals the LOphonon energy, $\hbar \omega_{0}=92 \mathrm{meV}$ for GaN. This supports these statements: (i) the dissipation is controlled by the LO phonons, and (ii) the noise temperature is close to the electron temperature.

According to Eq. (4) the power dissipation rate depends on the hot-phonon lifetime. When $F=1$ is assumed [19], the effective hot-phonon lifetime $\tau_{\mathrm{ph}}^{*}$ is obtained. The effective lifetime tends to the hot-phonon lifetime in a degenerate electron gas.

Expression (4) is applicable at low temperatures, $k_{\mathrm{B}} T_{0} \ll \hbar \omega_{0}$. At an elevated temperature, the equilibrium LO-phonon occupancy enters the modified semiempiric expression [7]:

$P_{\mathrm{d}}=A\left[\left(\exp \frac{\hbar \omega_{0}}{k_{\mathrm{B}} T_{\mathrm{n}}}-1\right)^{-1}-\left(\exp \frac{\hbar \omega_{0}}{k_{\mathrm{B}} T_{0}}-1\right)^{-1}\right]$

Expression (5) fits the experimental data for degenerate $2 \mathrm{D}$ and non-degenerate $3 \mathrm{D}$ electron gas channels [7,31]. The dependence of $F$ on electron density is important for the 3D channel. 


\section{Comparison with Raman data}

As mentioned, the most direct way for hot-phonon lifetime measurement is femtosecond time-resolved pump-probe Raman light scattering technique. However, up to now, no Raman datum of this sort is reported for a 2D channel with a degenerate electron gas of interest for contemporary high-speed transistors. The fluctuation technique [19] was developed and provided with the pioneering result on the hot-phonon lifetime in the 2D channel located in the GaN layer at the heterojunction with AlGaN (Fig. 3, closed circle). The reported lifetime was an order of magnitude shorter than the Raman value measured at a relatively low electron density for GaN [14] (open square). There was no datum for $\mathrm{GaN}$ at a high density of electrons for immediate comparison. Therefore, the fluctuation technique was checked on boron-doped Si (open diamond [32]), and a reasonably good agreement with the data [33] was obtained when the known density dependence of the lifetime was taken into account. The fluctuation data for different 2D and 3D channels (Fig. 3, open triangle [34], open diamond [32], black diamond [35], black square [6]) find themselves close to the squareroot dependence (solid line) expected for hot-phonon disintegration assisted by plasmons $[6,16]$. The hypothetic square-root dependence is confirmed by the recent femtosecond pump-probe Raman experiment carried out for GaN bulk crystals at different intensity of the pump excitation [15] (open circles).

The first result for a 2D channel with a degenerate electron gas (Fig. 3, closed circle [19]) was confirmed two years later by the time-resolved LOphonon-assisted inter-sub-band infrared-absorption experiment carried out for a similar $\mathrm{AlGaN} / \mathrm{GaN}$ channel (black down-triangle [20]). The obtained values nearly coincide (closed circle and black down-triangle). In the range of high density, they are close to the Raman data (open circles). Thus, the novel fluctuation technique is approved through the comparison of the results with those obtained by two different response techniques.

\section{The unique application}

Raman data show that the lifetime depends on ambient temperature $[13,15]$. This behaviour is observed at a low density of electrons and interpreted in terms of disintegration of hot phonons into acoustic phonons and transverse optical phonons [14]. As mentioned, another mechanism - the plasmon-assisted disintegration - turns on at a high density of plasma [16]. This

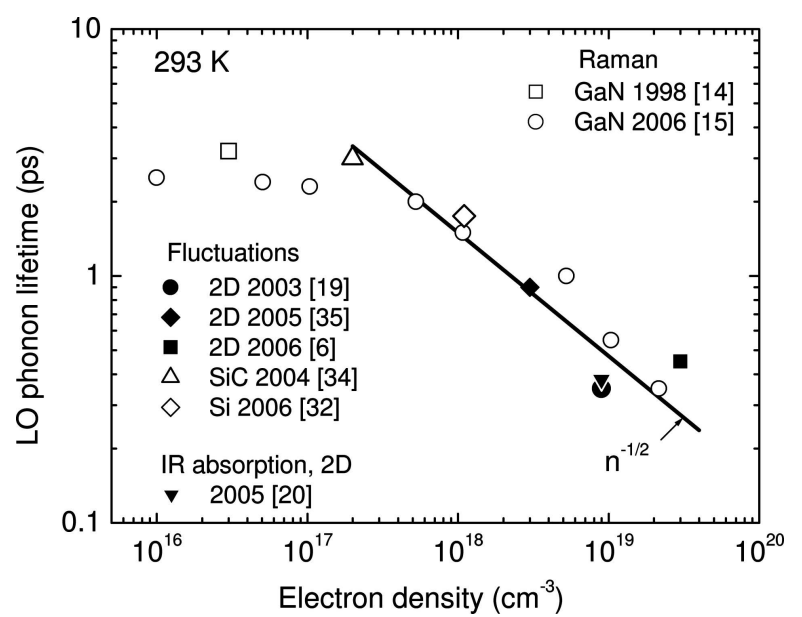

Fig. 3. Hot-phonon lifetime at different electron density (or electron-hole plasma density) for 2D channels (closed symbols) and bulk single crystals (open symbols) at room temperature. Fluctuation data for 2D channels: $\mathrm{AlGaN} / \mathrm{GaN}$ (closed circle [19]), AlInAs / GaInAs / AlInAs (black diamond [35]), AlGaN/ AlN/GaN (black square [6]). Fluctuation data for 3D channels: 4H-SiC (open up-triangle [34]) and $\mathrm{Si}$ (open diamond [31]). Raman data for GaN (open square [14] and open circles [15]). Black down-triangle stands for LO-phonon-assisted inter-sub-band absorption experiment for a 2D channel located in AlGaN/GaN [20]. Solid line stands for $n^{-1 / 2}$-dependence.

mechanism is expected to dominate in 2D channels with degenerate electron gas [6]. Consequently, one can expect a different dependence on ambient temperature for 2D channels. Figure 4 illustrates the results of the fluctuation technique obtained at different ambient temperatures and different electron temperatures for nitride 2D channels $[19,36]$. The dependence of the lifetime on the channel temperature is weak if any (triangles). Neither the dependence on electron temperature is strong. At a high density of electrons the hot-phonon lifetime and the electron energy relaxation time tend to merge as the electric field increases [6, 37]. They exceed the energy relaxation time estimated neglecting hot phonons [38].

Figure 4 illustrates the unique potential of the fluctuation technique: neither the time-resolved infrared absorption nor the Raman technique have been used to measure the dependence of the hot-phonon lifetime on the electron temperature in a voltage-biased 2D channel with a degenerate electron gas of interest for highspeed HEMTs.

\section{Conclusions}

The fluctuation technique has demonstrated its potential in experimental investigation of hot-phonon lifetime in voltage-biased 2D and 3D channels of in- 


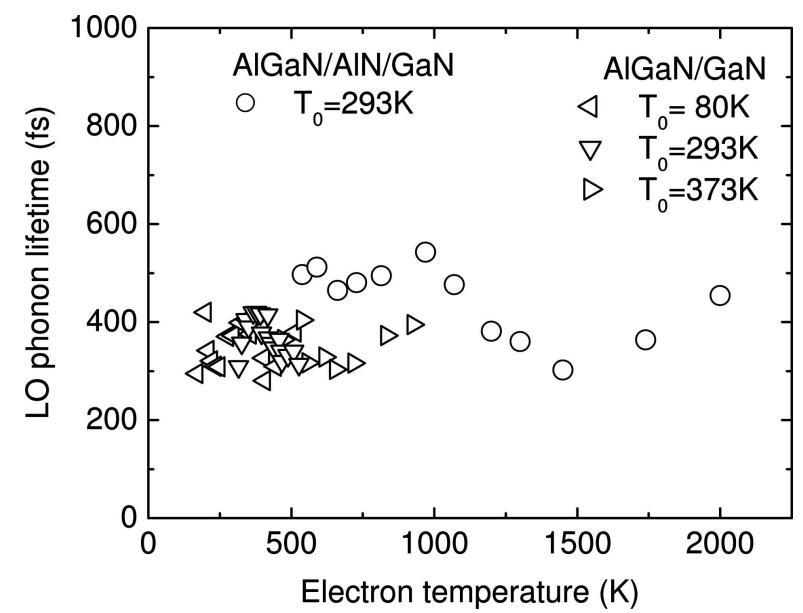

Fig. 4. Dependence of hot-phonon lifetime on electron temperature at different ambient temperature $T_{0}$ for nitride $2 \mathrm{D}$ channels: AlGaN/GaN (triangles [36]): $T_{0}=80 \mathrm{~K}$ (left triangles), $T_{0}=$ $293 \mathrm{~K}$ (down triangles), $T_{0}=373 \mathrm{~K}$ (right triangles). AlGaN/ AlN $/ \mathrm{GaN}: T_{0}=293 \mathrm{~K}$ (circles [6]).

terest for modern high-speed electronics. The fluctuation technique yields similar lifetimes if electron density in a $2 \mathrm{D}$ channel is comparable with that of the electron-hole plasma generated by a femtosecond laser in a bulk crystal during pump-probe Raman experiments. The result on the lifetime in AlGaN/GaN channel is in a good agreement with the value for a similar heterostructure obtained through the time-resolved LOphonon-assisted infrared absorption experiment.

\section{References}

[1] A. Matulionis, Noise, hot carrier effects, in: Wiley Encyclopedia of Electrical and Electronics Engineering, Vol. 14, ed. J.G. Webster (Wiley, New York, 1999) pp. 410-428.

[2] H.L. Hartnagel, R. Katilius, and A. Matulionis, Microwave Noise in Semiconductor Devices (Wiley, New York, 2001).

[3] A. Matulionis, V. Aninkevičius, and J. Liberis, Hotelectron velocity fluctuations in two-dimensional electron gas channels, Microelectron. Rel. 40(11), 18031814 (2000).

[4] A. Matulionis and I. Matulionienè, Hot-electron noise in III-V semiconductor structures for ultrafast devices, in: Noise and Fluctuations Control in Electronic Devices, ed. A.A. Balandin (Stevenson Ranch, American Scientific Publishers, 2002) pp. 249-266.

[5] P. Kocevar, Hot phonon dynamics, Physica B\&C 88(13), 155-163 (1985).

[6] A. Matulionis, Hot phonons in $\mathrm{GaN}$ channels for HEMTs, Phys. Status Solidi A 203(10), 2313-2325 (2006).
[7] A. Matulionis and I. Matulioniene, Accumulation of hot phonons in $\mathrm{GaN}$ and related structures, invited in: Proceedings of SPIE on Gallium Nitride Materials and Devices II, Vol. 6473, eds. H. Morkoç and C.W. Litton (SPIE, Washington, 2007) pp. 64730P-1-15.

[8] D. Streit, InP MMICs for radiometer applications, in Proceedings of the WOCSDICE 2007, ed. G. Meneghesso (University of Padova, 2007) p. 163.

[9] T. Palacios, A. Chakraborty, S. Heikman, S. Keller, S.P. DenBaars, and U.K. Mishra, AlGaN/GaN high electron mobility transistors with InGaN back-barriers, IEEE Electron Device Lett. 27(1), 13-15 (2006).

[10] M. Higashiwaki, T. Matsui, and T. Mimura, AlGaN/ GaN MIS-HFETs with $f_{\mathrm{T}}$ of $163 \mathrm{GHz}$ using cat-CVD $\mathrm{SiN}$ gate-insulating and passivation layers, IEEE Electron Device Lett. 27(1), 16-18 (2006).

[11] M. Artaki and P.J. Price, Hot phonon effects in silicon field effect transistors, J. Appl. Phys. 65(3), 1317-1320 (1989).

[12] B.K. Ridley, W.J. Schaff, and L.F. Eastman, Hotphonon-induced velocity saturation in GaN, J. Appl. Phys. 96(3), 1499-1502 (2004).

[13] J.A. Kash and J.C. Tsang, Nonequilibrium phonons in semiconductors, in: Spectroscopy of Nonequilibrium Electrons and Phonons, eds. C.V. Shank and B.P. Zakharchenya (Elsevier, North Holland, 1992) pp. 113166.

[14] K.T. Tsen, D.K. Ferry, A. Botchkarev, B. Sverdlov, A. Salvador, and H. Morkoç, Time-resolved Raman studies of the decay of the longitudinal optical phonons in wurtzite GaN, Appl. Phys. Lett. 72(17), 2132-2134 (1998).

[15] K.T. Tsen, J.G. Kiang, D.K. Ferry, and H. Morkoç, Subpicosecond time-resolved Raman studies of LO phonons in GaN: Dependence on injected carrier density, Appl. Phys. Lett. 89(11), 112111-1-3 (2006).

[16] B.K. Ridley and A. Dyson, The lifetime of coupled plasmon-phonon modes, in: Proceedings of the WOCSDICE 2007, ed. G. Meneghesso (University of Padova, 2007) pp. 225-228.

[17] K.T. Tsen and H. Morkoc, Population relaxation time of nonequilibrium LO phonons and electron-phonon interactions in $\mathrm{GaAs}-\mathrm{Al}_{x} \mathrm{Ga}_{1-x}$ As multiple-quantumwell structures, Phys. Rev. B 34(6), 4412-4414 (1986).

[18] M.C. Tatham, J.F. Ryan, and C.T. Foxon, Timeresolved Raman scattering measurement of electronoptical phonon intersubband relaxation in GaAs quantum wells, Solid-State Electron. 32(12), 1497-1501 (1989).

[19] A. Matulionis, J. Liberis, I. Matulionienè, M. Ramonas, L.F. Eastman, J.R. Shealy, V. Tilak, and A. Vertiatchikh, Hot-phonon temperature and lifetime in a biased $\mathrm{Al}_{x} \mathrm{Ga}_{1-x} \mathrm{~N} / \mathrm{GaN}$ channel estimated from noise analysis, Phys. Rev. B 68(3), 035338-1-7 (2003).

[20] Z. Wang, K. Reimann, M. Woerner, T. Elsaesser, D. Hofstetter, J. Hwang, W.J. Schaff, and L.F. East- 
man, Optical phonon sidebands of electronic intersubband absorption in strongly polar semiconductor heterostructures, Phys. Rev. Lett. 94(3), 037403-1-4 (2005).

[21] Sh.M. Kogan and A.Ya. Shul'man, Electric fluctuations in solid state plasma at high electric fields, Fiz. Tverd. Tela 9(8), 2259-2264 (1967) [Sov. Phys. Solid State 9(8), 1771 (1968)].

[22] R. Katilius and M. Rudan, Noise as a tool for tracing effects of nonclassical correlations in a degenerate nonequilibrium electron gas, Phys. Rev. B 74(23), 233101-1-4 (2006).

[23] M. Ramonas, A. Matulionis, J. Liberis, L.F. Eastman, X. Chen, and Y.J. Sun, Hot-phonon effect on power dissipation in a biased $\mathrm{Al}_{x} \mathrm{Ga}_{1-x} \mathrm{~N} / \mathrm{AlN} / \mathrm{GaN}$ channel, Phys. Rev. B 71(7), 075324-1-8 (2005).

[24] M. Ramonas and A. Matulionis, Monte Carlo simulation of hot-phonon effects in biased nitride channels, in: New Research on Semiconductors, ed. T.B. Elliot (Nova Science Publishers, 2006) pp. 95-121.

[25] A. Matulionis, J. Liberis, and M. Ramonas, Microwave noise in biased $\mathrm{AlGaN} / \mathrm{GaN}$ and $\mathrm{AlGaN} / \mathrm{AlN} / \mathrm{GaN}$ channels, in: AIP Conf. Proc. Noise and Fluctuations, Vol. CP780, eds. T. González, J. Mateos, and D. Pardo (AIP, New York, 2005) pp. 105-108.

[26] N. Shigekawa, K. Shiojima, and T. Suemitsu, Optical study of high-biased AlGaN/GaN high-electronmobility transistors, J. Appl. Phys. 92(1), 531-535 (2002).

[27] K. Wang, J. Simon, N. Goel, and D. Jena, Optical study of hot-electron transport in GaN: Signatures of the hotphonon effect, Appl. Phys. Lett. 88(2), 022103-1-3 (2006).

[28] A. Matulionis, J. Liberis, L. Ardaravičius, M. Ramonas, I. Matulionienè, and J. Smart, Hot-electron energy relaxation time in $\mathrm{AlGaN} / \mathrm{GaN}$, Semicond. Sci. Technol. 17(3), L9-L14 (2002).

[29] A. Matulionis, R. Katilius, J. Liberis, L. Ardaravičius, L.F. Eastman, J.R. Shealy, and J. Smart, Hot-electron temperature relaxation time in a 2-DEG: AlGaN/GaN at 80 K, J. Appl. Phys. 92(8), 4490-4497 (2002).

[30] A. Matulionis, J. Liberis, L. Ardaravičius, M. Ramonas, T. Zubkutè, I. Matulionienè, L.F. Eastman, J.R. Shealy, J. Smart, D. Pavlidis, and S. Hubbard, Fast and ultrafast processes in AlGaN/GaN, Phys. Status Solidi B 234(3), 826-829 (2002).

[31] J. Liberis, M. Ramonas, O. Kiprijanovic, A. Matulionis, N. Goel, J. Simon, K. Wang, H. Xing, and D. Jena, Hot phonons in Si-doped GaN, Appl. Phys. Lett. 89(20), 202117-1-3 (2006).

[32] J. Liberis, I. Matulionienè, A. Matulionis, M. Lemme, H. Kurz, and M. Först, Hot-phonon temperature and lifetime in biased boron-implanted $\mathrm{SiO}_{2} / \mathrm{Si} / \mathrm{SiO}_{2}$ channels, Semicond. Sci. Technol. 21(6), 803-807 (2006).

[33] M. Hase, M. Kitajima, A.M. Constantinescu, and H. Petek, The birth of a quasiparticle in silicon observed in time-frequency space, Nature 426(6962), 51-92 (2003).

[34] A. Matulionis, J. Liberis, I. Matulionienè, H.Y. Cha, L.F. Eastman, and M.G. Spencer, Hot-phonon temperature and lifetime in biased $4 \mathrm{H}-\mathrm{SiC}$, J. Appl. Phys. 96(11), 6439-6444 (2004).

[35] V. Aninkevičius, A. Matulionis, and I. Matulionienè, Hot-phonon lifetime in a modulation-doped AlInAs / GaInAs / AlInAs / InP, Semicond. Sci. Technol. 20(2), 109-114 (2005).

[36] A. Matulionis, J. Liberis, L. Ardaravičius, L.F. Eastman, J.R. Shealy, and A. Vertiatchikh, Hot-phonon lifetime in $\mathrm{AlGaN} / \mathrm{GaN}$ at high lattice temperatures, Semicond. Sci. Technol. 19(4), S421-S423 (2004).

[37] A. Matulionis and J. Liberis, Microwave noise in AlGaN/GaN channels, IEE Proc. Circuits Devices Syst. 151(2), 148-154 (2004).

[38] T. Zubkutė and A. Matulionis, Hot-electron energy dissipation and interelectron collisions in GaN-WZ, Semicond. Sci. Technol. 17(11), 1144-1148 (2002).

\title{
FLIUKTUACINIAI METODAI LABAI SPARTIEMS VYKSMAMS TIRTI
}

\author{
A. Matulionis \\ Puslaidininkių fizikos instituto Fliuktuacinių reiškinių laboratorija, Vilnius, Lietuva
}

\section{Santrauka}

Fliuktuaciniai metodai karštujju elektronu energijos relaksacijos, tarpslènių šuolių, šuolių tarp kanalų, karštųjų fononų pusamžio ir kitų labai sparčių vyksmų eksperimentiniam tyrimui puslaidininkiuose ir jų dariniuose sèkmingai varžosi su labiau iprastais atsako metodais. Optinių fononu pusamžis darinyje su dvimačiu srovès kanalu pirmą kartą išmatuotas būtent fliuktuaciniu, o ne kokiu kitu metodu. Šis rezultatas tik po poros metų buvo patvirtintas tiriant fononais skatinamą spinduliuotès sugertị. Rezultatai gerai dera su pusamžiu, kuris neseniai buvo išmatuotas Ramano šviesos sklaidos metodu. Vis dèlto Ramano metodu dar iki šiol neišmatuotas fononu pusamžis elektronikai svarbiame dvimačiame kanale su didelio tankio elektronų dujomis. Taip pat šiuo metu dar nežinomas joks kitas metodas, be fliuktuacinio, tinkamas matuoti fononų pusamžio priklausomybei nuo karštụjų elektronų temperatūros. Fliuktuacinių metodų reikšmė auga, mažèjant darinių matmenims. 